\title{
Application of the RAFLS model for integrated water resource management for the Itezhi-Tezhi/Kafue river system
}

\author{
Humphrey Sinyangwe ${ }^{1 *}$ and David Stephenson ${ }^{2}$ \\ ${ }^{1}$ School of Civil and Environmental Engineering, University of the Witwatersrand, Private Bag 3, 2050 Wits, Johannesburg, South Africa \\ ${ }^{2}$ Dept. Civil Engineering, University of Botswana, Private Bag 0061, Gaborone, Botswana
}

\begin{abstract}
The modelling system could be a tool for predicting the flow regime in water management operations. The modified RAFLS model has exhibited a profound accuracy in the simulations of the Itezhi-tezhi/Kafue River system. The simulated flows and reservoir levels portrayed the dynamics in terms of time and magnitude.

The use of the RAFLS model for water management in the subcatchment will result in flood protection, less evaporation from the shallow and wide natural reservoir, the Kafue Gorge Reservoir, available grazing grounds for the local communities, reclaimed fertile flood plains for farming by the local people, favourable flow regime for the ecological system, land use and efficient release of water from the reservoirs that would enhance conservation for drought situations.
\end{abstract}

Keywords: modelling, prediction, water management, Kafue Gorge Reservoir, Zambia

\section{Introduction}

Chapman et al.(1975) define flood routing or stream routing as the process of calculating the hydrograph at the downstream end of a reach given the hydrograph at the upstream end. Wilson (1974) describes flood routing as the procedure through which the variation of discharge with time at a point on a stream channel may be determined by consideration of similar data for a point upstream. Chapra (1997) recounts that a spectrum of models that are available to simulate dynamic water movement for streams are based on the St. Venant equations. The latter result from taking mass and momentum balances on a one-dimension channel.

Stakeholders including environmentalists, farmers, fishermen, wildlife department, local authorities, etc. have expressed grave concern over the water resource management of the Itezhitezhi (ITT)/Kafue River system in Zambia in the past three decades. Stephenson and Randell (2000) state that complex systems require computer modelling to maximise the output.

This system consists of three reservoirs, two regulated and one unregulated. The regulated are Itezhi-tezhi Reservoir with a full capacity of $6000000 \mathrm{~m}^{3}$ and Kafue Gorge with a full capacity of $800000 \mathrm{~m}^{3}$. The non-regulated is the natural reservoir with a capacity of about $3000000 \mathrm{~m}^{3}$. The average annual flow for the Kafue River is $300 \mathrm{~m}^{3} / \mathrm{s}$ (Source: ZESCO database).

Concerns hinge on the water management scenarios that have been implemented by the water managers, viz. ZESCO Limited. Some stakeholders dispute that the water level fluctuations in the reach do not mimic the natural or the previous unregulated flows; hence, this has substantially affected aquatic, animal and human lives, resulting in the following:

- Agriculture: The local people who rear animals complain about the persistently high water levels that do not recede,

\footnotetext{
* To whom all correspondence should be addressed.

II: +2601 229542; fax: +2601229542;

e-mail: hsinyangwe@zesco.co.zm

Received 3 December 2004; accepted in revised form 26 May 2005
}

therefore allowing no shooting of grazing grass during summer. The other problem is that they are unable to practice their traditional 'recession agriculture' with receding water levels.

- Fisheries: The breeding and migratory patterns of most fishes have been severely disrupted due to lack of flooding or poor timing of regulated flooding.

- Wildlife: The feeding and breeding grounds are known to have been lost due to low flooding during the rainy season and high flooding during the dry season (Rees, 1978; Chabwela and Ellenbroek, 1990).

A considerable number of studies have recently been conducted in the above-mentioned river system; however, the recommendations are hardly implemented. To some extent this has been due to non-inclusion of ZESCO Limited who handle the water management, in the technical deliberations, and specialists from other fields tend to be biased. Hence, some of the recommendations made prove to be unattainable because they are merely theoretical.

In 2001 World Wide Fund for Nature (WWF) initiated the Integrated Water Management Project for the Kafue Flats (the area between Itezhi-tezhi and Kafue Gorge Reservoirs, Fig. 1). The Project's main concern was the preservation of the wetlands environment of the area liable to flooding (WWF, 2004). KAFRIBA Model was one of the supporting tools in decision making for the operation of the Itezhi-tezhi and Kafue Gorge Reservoirs.

However, in order to narrow the rift between the stakeholders' expectations and the water manager's operations, a modified RAFLS Model that integrates variant interests in the water resources management on the Itezhi-tezhi/Kafue River system is presented in this paper.

\section{Study area}

The Itezhi-tezhi/Kafue River system stretches along the Kafue River from Itezhi-tezhi Reservoir to Kafue Gorge Reservoir (Fig. 1). Downstream of the Itezhi-tezhi Dam the subcatchment 


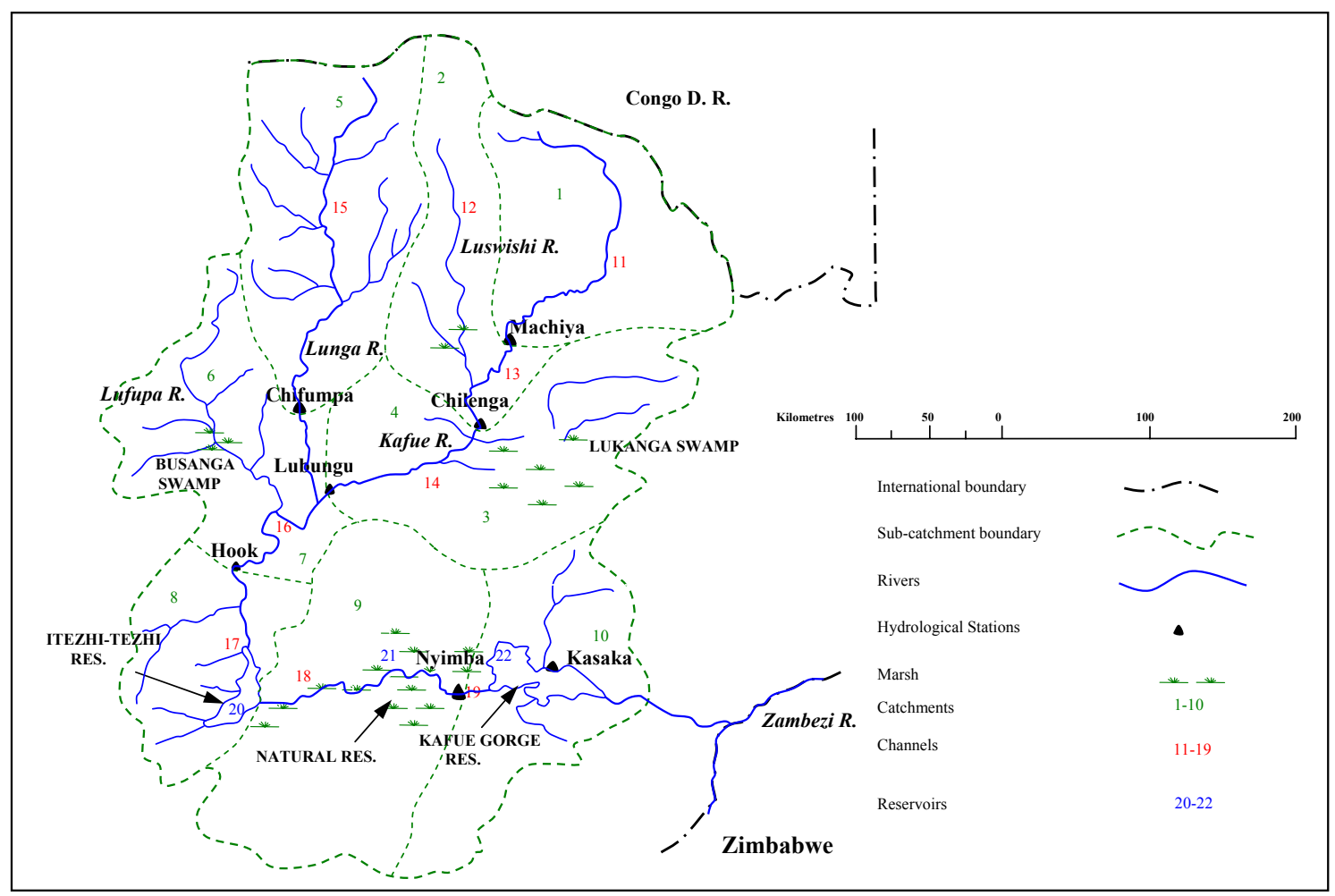

Figure 1

The Kafue catchment (Source: Sinyangwe, 2004)

is called the Kafue Flats, because of its gentle slope from the west to the east with a drop of about $6 \mathrm{~m}$ in about $230 \mathrm{~km}$ (Harza, 1999). The Kafue Flats subcatchment has an area of $41074 \mathrm{~km}^{2}$. This area has a high population of diverse activities and it is also a haven for wildlife. The wetland covers some 4380 to $7000 \mathrm{~km}^{2}$ of land (Scott, 2003). About 30 small tributaries drain into the Kafue Flats (Harza, 1999). The main tributaries are Mansenga, Nagoma, Mwembeshi, Musa, Nkole, Nanzila, Mutama, Ngwesi and Kaleya. Most of these are non-perennial and are subject to flash floods that inundate the depression and sloughs. On the right bank of the Kafue River most of the water from tributaries is dammed and used for irrigation.

The meandering river channel is bounded by discontinuous levees on both banks and has an elevated section of the river bank near Kasaka Hydrological Station (Fig. 1); the latter acted as a natural control on outflow from the flats into the Gorge, before the construction of the Kafue Gorge Reservoir.

The conveyance capacity of the channel immediately downstream of Itezhi-tezhi Reservoir is estimated to be about $250 \mathrm{~m}^{3} / \mathrm{s}$ (DHV, 1980; Handlos and Williams, 1984) and thereafter it becomes less distinct encompassing multiple channels and open water depressions.

\section{The KAFRIBA Model}

The original model, Ribasi was developed by DHV Consulting Engineers between 1978 and 1980 as part of Kafue Flats Hydrological Studies (WWF, 2004).

KAFRIBA simulates the hydrodynamic behaviour of the Kafue Flats. It predicts water levels in the reservoirs and the hydrodynamic flooding patterns in the Flats for various scenarios. The major feature of the model is the simulation of the natural situation, as if the reservoirs were not present. It also gives a graphical presentation of the flooding patterns for both situations, with and without reservoirs.

\section{Adoption of the RAFLS Model}

The Water Systems Research Group of the University of the Witwatersrand developed the Rainfall Flow Simulation (RAFLS) Rainfall-Runoff Event Simulation Model using macros in visual basic application (VBA) and the program is interfaced with an EXCEL spreadsheet for its input and output data. The modelling considered in this paper is known as deterministic modelling, i.e. it is based on complex physical theory regarding a single flood event. The model endeavours to represent mathematically the many events that occur in the rainfall-runoff process (Cousens and Burney, 1976).

However, in order to make the above-mentioned model appropriate for the water management operations some model parameters and algorithms had to be altered. The modifications were done for two reasons:

- To accommodate the available information for the study area for the enhancement of results

- To enable the model to produce the required output

The major changes included the breadth, length, bank slope and the spillway depth for the reservoir modules. The model now has the capability to compute the reservoir levels at any selected time interval. For certain model processes that require reservoir levels to be derived, the elevation-storage ratings were introduced. In the case of the natural (unregulated) reservoir, outflows were also part of the rating. Controlled outflows / releases were initiated for the regulated reservoirs as part of the input data. In the output file, apart from the flow column and its corresponding hydrograph plot, a column for the reservoir levels with its hydrograph plot were included. Besides, the model now 


\begin{tabular}{|l|c|c|c|c|c|c|c|c|}
\hline \multicolumn{7}{|c|}{ TABLE 1 } \\
\hline $\begin{array}{l}\text { Mod } \\
\text { No. }\end{array}$ & $\begin{array}{c}\text { Ave. } \\
\text { slope }\end{array}$ & $\begin{array}{c}\text { DRO }^{+} \\
\mathbf{( \% )}\end{array}$ & $\begin{array}{c}\text { Manning's } \\
\text { No. }\end{array}$ & Rill ratio & $\begin{array}{c}\text { Vert. perm. } \\
(\mathbf{m m} / \mathbf{h})\end{array}$ & $\begin{array}{c}\text { Horiz. } \\
\text { perm. } \\
(\mathbf{m m} / \mathbf{h})\end{array}$ & $\begin{array}{c}\text { Porosity } \\
\text { (fraction) }\end{array}$ & $\begin{array}{c}\text { Soil } \\
\text { suction } \\
(\mathbf{m})\end{array}$ \\
\hline 9 & 0.00512 & 2.2 & 0.20 & 0.3 & 5.0 & 0.05 & 0.3 & 1.0 \\
\hline 10 & 0.00319 & 2.2 & 0.20 & 0.3 & 5.0 & 0.05 & 0.3 & 1.0 \\
\hline${ }^{+}$Direct runoff
\end{tabular}

\begin{tabular}{|c|c|c|c|c|c|c|}
\hline \multicolumn{7}{|c|}{$\begin{array}{c}\text { TABLE } 2 \\
\text { Parameters of the river modules }\end{array}$} \\
\hline \multicolumn{2}{|c|}{ Module } & \multirow{2}{*}{$\begin{array}{l}\text { Length } \\
(\mathrm{m})\end{array}$} & \multirow{2}{*}{$\begin{array}{l}\text { Width } \\
\text { (m) }\end{array}$} & \multirow{2}{*}{$\begin{array}{l}\text { Ave. } \\
\text { scope }\end{array}$} & \multirow{2}{*}{$\begin{array}{l}\text { Manning's } \\
\text { No. }\end{array}$} & \multirow{2}{*}{$\begin{array}{l}\text { Side } \\
\text { slope }\end{array}$} \\
\hline No. & Description & & & & & \\
\hline 18 & Module No. 20 to Nyimba & 214146 & 1000 & 0.00002 & 0.070 & 3.0 \\
\hline 19 & Nyimba to module No. 22 & 140976 & 1000 & 0.00002 & 0.070 & 3.0 \\
\hline
\end{tabular}

allows for a determined initial flow in the channel modules.

The reservoir outflows are either computed by the model from the storage-outflow rating for the unregulated reservoir or predetermined for regulated reservoirs. Note that the turbine discharge from the hydropower station is considered as the reservoir outflow.

\section{Input data and parameter estimations}

The historical hydrological data were obtained from the ZESCO database. These included: the daily water levels for the natural reservoir, Itezhi-tezhi Reservoir and the Kafue Gorge Reservoir, daily outflows from the Itezhi-tezhi and the Kafue Gorge Reservoirs, and daily flows of Kafue River at Nyimba hydrological station (Fig. 1).

Model parameters were derived with the aid of historical records of the catchment and the 1:250 000 maps. However, for some empirical parameters that had the highest degree of uncertainty, the values were limited to hydrologically acceptable ranges during the adjustments, while focusing attention on those parameters to which model results are most sensitive. Some parameter values were estimated on the basis of published data, general knowledge of likely values, intuition, rational consideration of the nature of the physical processes, or from relationships of values with measures of catchment characteristics and antecedent conditions. Beven (2001) notes that studies that have attempted using intensive series of measurements of parameter values have proven to be unsatisfactory, although some form of optimisation of the parameter values by comparing the results of repeated simulations with the observed catchment response was done.

The sensitivity analyses were carried out for ascertaining the model response to individual parameters in circumstances with a degree of inaccuracy. The attention was also drawn to more sensitive parameters.

Tables 1 and 2 show a summary of the model parameter values for the study area (Source: Sinyangwe, 2004).

\section{Model application}

In this section the model's capability in water management operations for the ITT/Kafue River system will be demonstrated. Firstly, the program can predict a time lag over which a particular flood release could be expected at a point, secondly it can also give the magnitude of the flow to be expected, and thirdly it can also give an attenuation pattern of a particular flood with the increased outflows at Kafue Gorge Reservoir.

In this demonstration, the dry season is deliberately chosen in order to authenticate a reasonable control of the water system with no influence from the rainfall activity. Besides, the two periods picked for the runs at each reservoir cover a period of average tributary contributions and that of extremely low tributary inflows. The illustrations will include some graphical comparisons of the simulated and the observed measurements.

Two sets of data were picked to conduct some runs for the natural and Kafue Gorge Reservoirs, respectively.

\section{Simulation runs}

Firstly, a demonstration of how the lag time and the magnitude of a particular released flow could be predicted at the two reservoirs. The water levels have been used for comparison purposes instead of the inflows because they are the only observed parameters. However, the hydrographs of the inflows into the reservoirs have been plotted. Secondly, the attenuation prediction of Kafue Gorge Reservoir is also demonstrated.

The total period for each run was 6 weeks. The estimated lag time for the flood release from Itezhi-tezhi Reservoir to Kafue Gorge Reservoir is between 4 and 6 weeks (SADC, 1993). The input data of the outflows at Itezhi-tezhi and Kafue Gorge Reservoirs for the simulation period were average flows of daily outflows for the 6 weeks' period. The results of the simulations were compared with the observed measurements and the deviations as tabulated. Note that the time step for the tabular comparison is every other day while for the graphical it is daily. For the graphical presentations of the inflows into the reservoirs, the time step is $2.5 \mathrm{~h}$ for the period of 6 weeks.

\section{Natural reservoir}

For the natural reservoir, the data sets commenced from 1 May 1995 for the first run while the second run was from 1 August 1996.

RAFLS was run for the two periods mentioned and the results are as shown in Tables 3 and 4, and Figs. 2, 3 and 4.

\section{Kafue Gorge Reservoir}

Similarly, the runs were done for Kafue Gorge Reservoir, the data sets commenced from 1 May 1995 for the first run while the second run was from 1 August 1995.

RAFLS was run for the two periods and the results are as shown in Tables 5 and 6, and Figs. 5, 6 and 7. 


\begin{tabular}{|c|c|c|c|}
\hline \multicolumn{4}{|c|}{ TABLE 3 } \\
Comparisons for natural reservoirs \\
from 01.05.95 \\
\cline { 1 - 3 } Day & \multicolumn{2}{|c|}{ Reservoir level (m) } & Deviation \\
\cline { 2 - 3 } & Simulated & Observed & (m) \\
\hline 1 & 978.32 & 978.34 & -0.02 \\
\hline 3 & 978.36 & 978.38 & -0.02 \\
\hline 5 & 978.40 & 978.42 & -0.02 \\
\hline 7 & 978.44 & 978.46 & -0.02 \\
\hline 9 & 978.49 & 978.50 & -0.01 \\
\hline 11 & 978.52 & 978.54 & -0.02 \\
\hline 13 & 978.55 & 978.58 & -0.03 \\
\hline 15 & 978.58 & 978.62 & -0.04 \\
\hline 17 & 978.61 & 978.67 & -0.06 \\
\hline 19 & 978.64 & 978.70 & -0.06 \\
\hline 21 & 978.67 & 978.74 & -0.07 \\
\hline 23 & 978.70 & 978.80 & -0.10 \\
\hline 25 & 978.72 & 978.83 & -0.11 \\
\hline 27 & 978.74 & 978.78 & -0.04 \\
\hline 29 & 978.76 & 978.78 & -0.02 \\
\hline 31 & 978.78 & 978.84 & -0.06 \\
\hline 33 & 978.79 & 978.83 & -0.04 \\
\hline 35 & 978.81 & 978.86 & -0.05 \\
\hline 37 & 978.82 & 978.89 & -0.07 \\
\hline 39 & 978.84 & 978.87 & -0.03 \\
\hline 41 & 978.85 & 978.83 & 0.02 \\
\hline 42 & 978.85 & 978.83 & 0.02 \\
\hline & & & \\
\hline & & \\
\hline
\end{tabular}

\begin{tabular}{|c|c|c|c|}
\hline \multicolumn{4}{|c|}{$\begin{array}{c}\text { TABLE } 4 \\
\text { Comparisons for natural reservoirs } \\
\text { from } 01.08 .96\end{array}$} \\
\hline \multirow[t]{2}{*}{ Day } & \multicolumn{2}{|c|}{ Reservoir level (m) } & \multirow{2}{*}{$\begin{array}{l}\text { Deviation } \\
\text { (m) }\end{array}$} \\
\hline & Simulated & Observed & \\
\hline 1 & 979.42 & 979.44 & -0.02 \\
\hline 3 & 979.37 & 979.46 & -0.09 \\
\hline 5 & 979.33 & 979.46 & -0.13 \\
\hline 7 & 979.28 & 979.48 & -0.20 \\
\hline 9 & 979.24 & 979.47 & -0.23 \\
\hline 11 & 979.19 & 979.47 & -0.28 \\
\hline 13 & 979.15 & 979.46 & -0.31 \\
\hline 15 & 979.11 & 979.41 & -0.30 \\
\hline 17 & 979.07 & 979.34 & -0.27 \\
\hline 19 & 979.03 & 979.27 & -0.24 \\
\hline 21 & 979.00 & 979.20 & -0.20 \\
\hline 23 & 978.97 & 979.13 & -0.16 \\
\hline 25 & 978.93 & 979.08 & -0.15 \\
\hline 27 & 978.90 & 978.99 & -0.09 \\
\hline 29 & 978.87 & 978.92 & -0.05 \\
\hline 31 & 978.84 & 978.83 & 0.01 \\
\hline 33 & 978.81 & 978.79 & 0.02 \\
\hline 35 & 978.79 & 978.74 & 0.05 \\
\hline 37 & 978.77 & 978.67 & 0.10 \\
\hline 39 & 978.75 & 978.59 & 0.16 \\
\hline 41 & 978.73 & 978.53 & 0.20 \\
\hline 42 & 978.71 & 978.49 & 0.22 \\
\hline
\end{tabular}

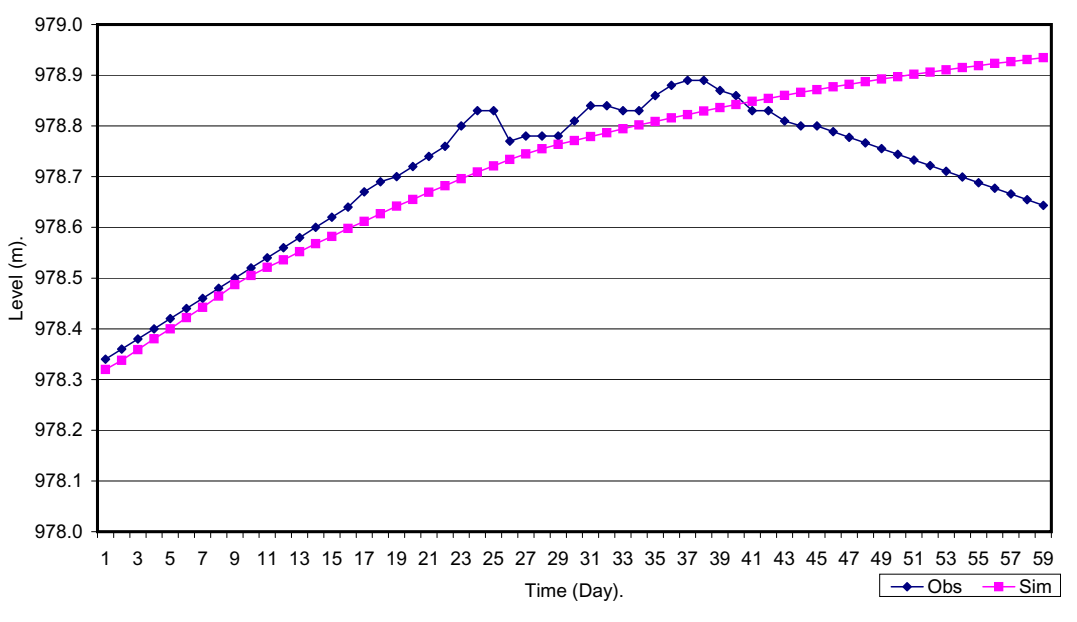

Figure 2

Comparison plot at natural reservoirs from 01.05.95

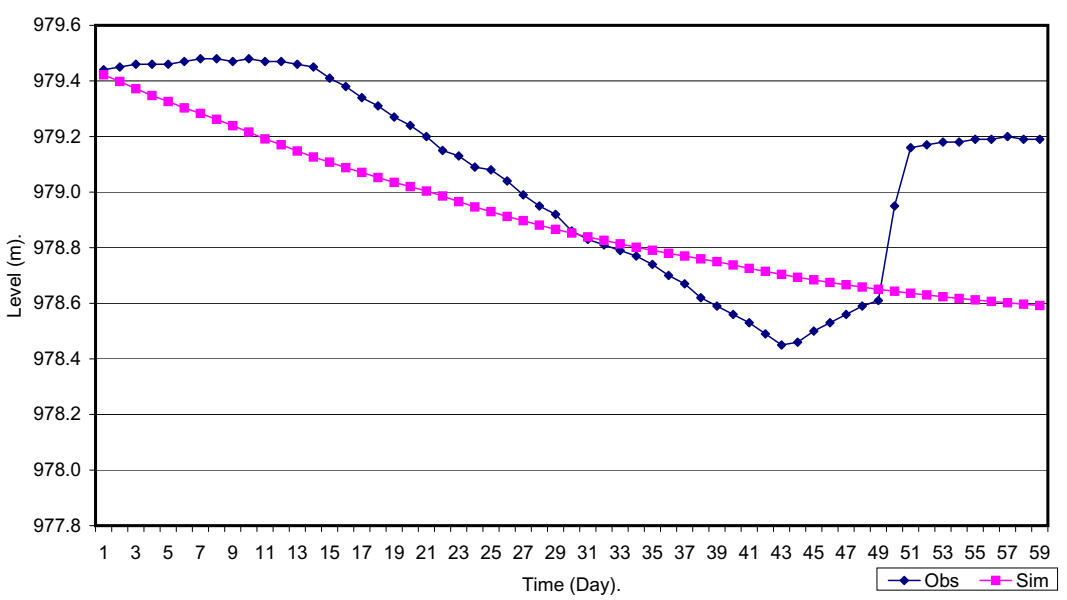

Figure 3

Comparison plot at natural reservoirs from 01.08.96

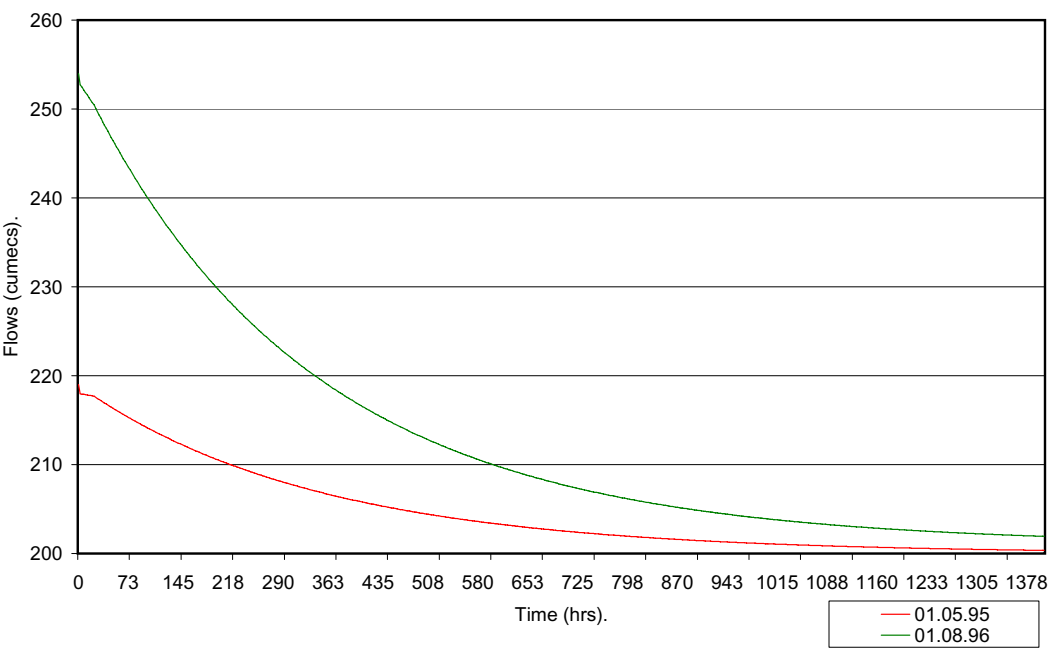

Figure 4

Hydrographs for the inflows into the natural reservoir

\section{Attenuation of Kafue Gorge Reservoir}

The attenuation capability of the model is demonstrated through the plot in Fig. 8 . Similar inflows were assumed for the reservoir while the outflows varied for the four different runs. 


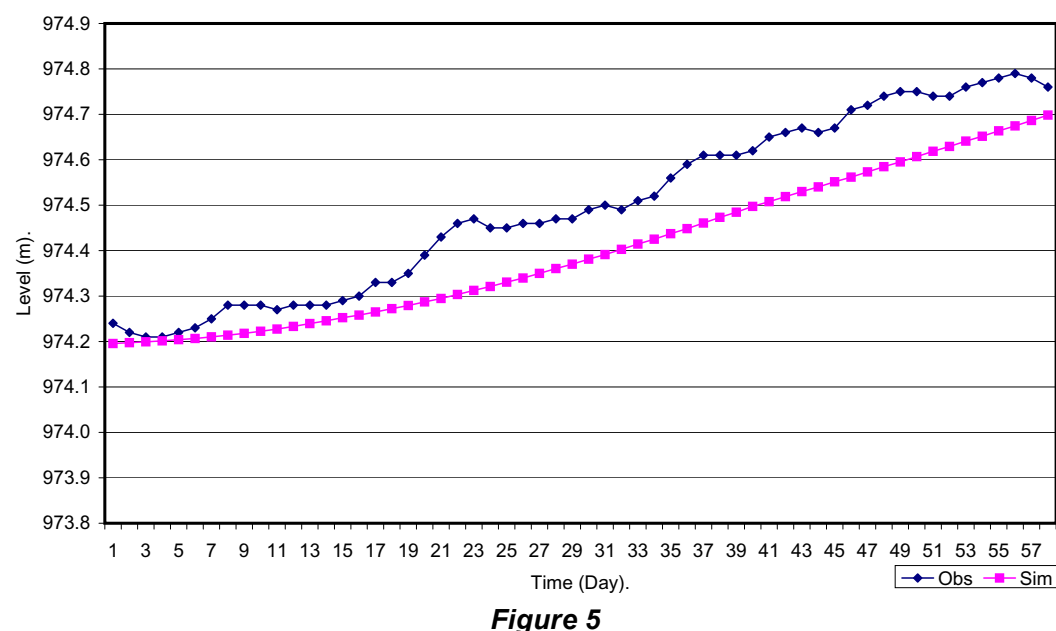

Comparison plot at Kafue Gorge Reservoir from 01.05.95

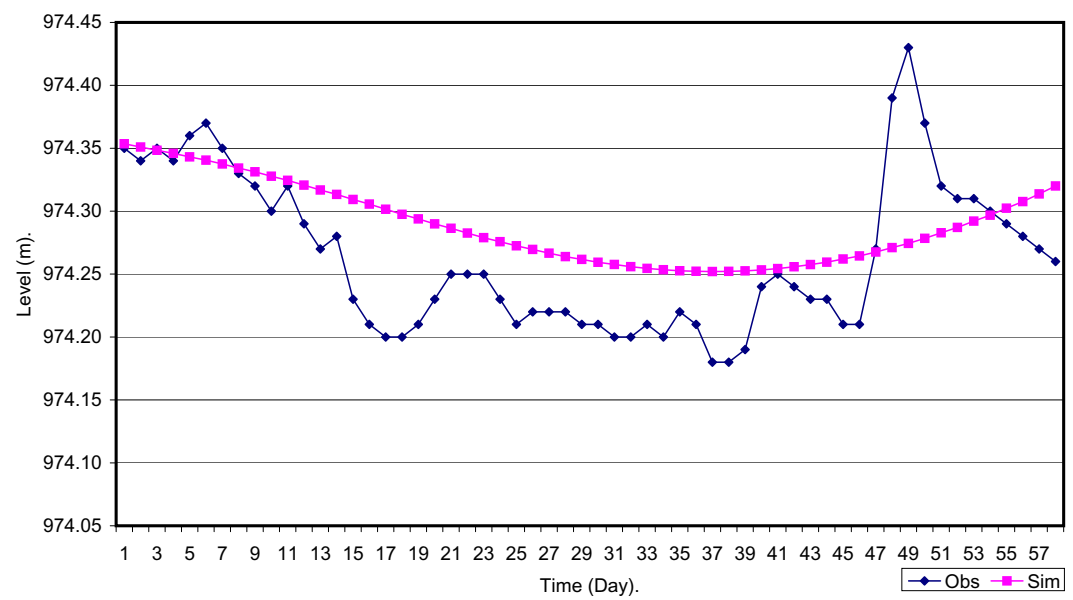

Figure 6

Comparison plot at Kafue Gorge Reservoir from 01.08.95

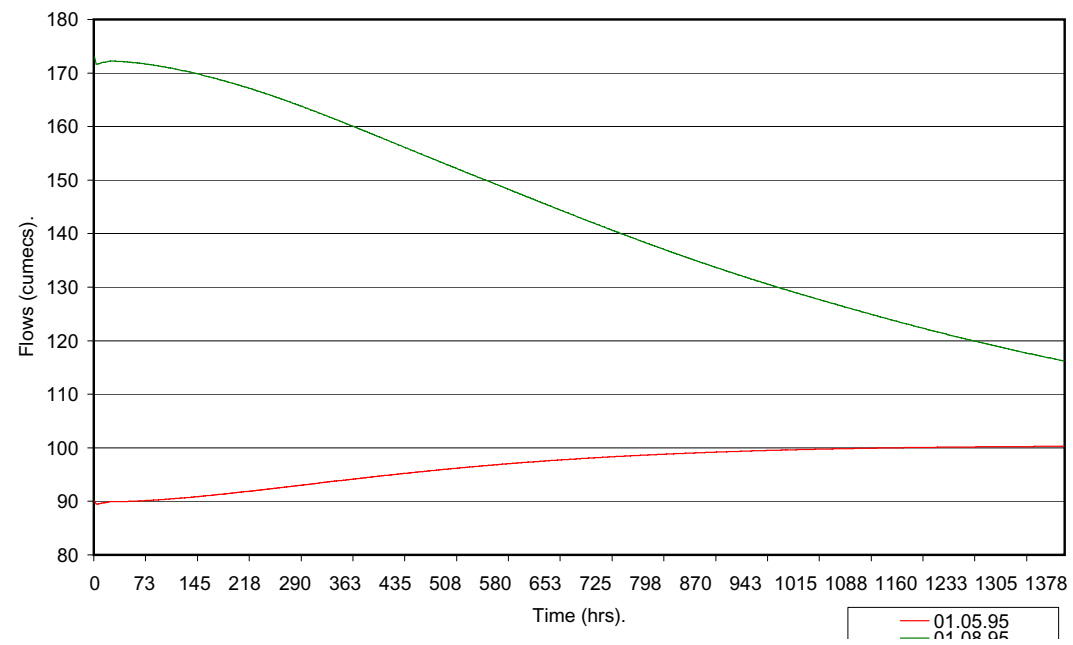

Figure 7

Hydrographs for the inflows into the Kafue Gorge Reservoir

\section{Discussions and conclusions}

The model proved to be capable of predicting the adverse effects of the operational regimes of the reservoirs as far as flooding was concerned. The predictions included the magnitude of the flood wave and the time lag at the monitoring stations. Besides,

\begin{tabular}{|c|c|c|c|}
\hline \multicolumn{4}{|c|}{ TABLE 5 } \\
Comparisons at Kafue Gorge Reser- \\
voir from 01.05.95
\end{tabular}

\begin{tabular}{|c|c|c|c|}
\hline \multicolumn{4}{|c|}{ TABLE 6 } \\
Comparisons at Kafue Gorge Reser- \\
voir from 01.08.95
\end{tabular}




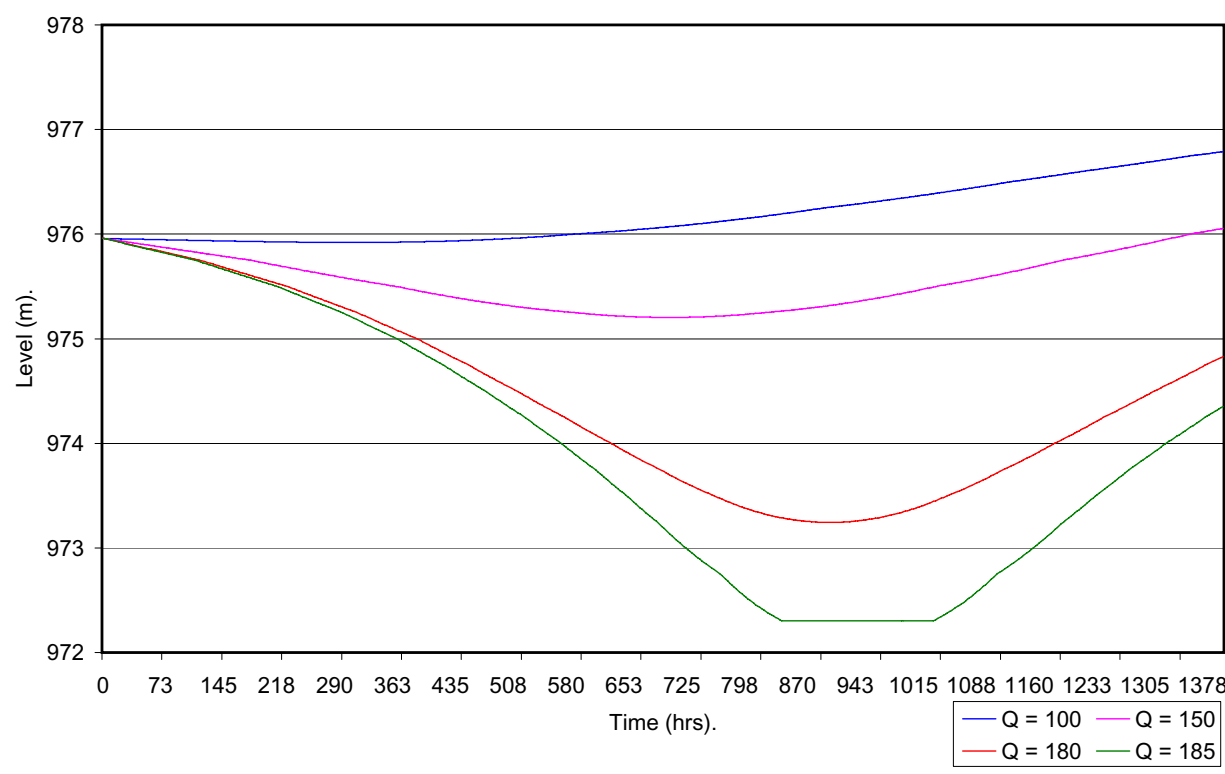

Figure 8

Simulated levels at Kafue Gorge with different outflows the model was able to determine how long the attenuation of the flooding was likely to be with a particular reservoir operation regime.

\section{Reservoir operations}

The Itezhi-tezhi and Kafue Gorge Reservoirs should be operated as multipurpose reservoirs. The latter implies that, apart from being storage reservoirs for power generation and flood control, ecological needs should also be given a relative weight that may exhibit seasonal variation.

The operational procedure or the routine operation of the reservoirs may be overruled during potential floods in order to minimise the flood hazards. One way of achieving this could be to employ 'real-time' flow forecasting techniques for advanced prediction of flow rates. The reservoir levels may then be drawn down by releasing storage prior to the arrival of the flood event. By this method storage is created that would result in an attenuation of the flood hydrograph. Depending on the lag time the local communities downstream should be given some advance warning of the impending flooding conditions, and thus allow them to be alert. Fleming (1975) observes that pre-releases from the reservoir are usually restricted to a quantity corresponding to the bankful in the downstream channel and are often limited to a total volume released equal to the 15 or $30 \mathrm{~d}$ normal baseflow rate so that the reservoir would fill up within that period if the flood forecast was in error.

The reservoir operational procedure should also consider the environmental and social issues. For instance, the specialist ecosystems that have evolved to depend on the dynamics of high and low water are not suited to the constant, average water levels that may be released for power generation. Therefore, the operational rule curves for the two reservoirs should accommodate or mimic the natural fluctuations in the river levels while at the same time not ignoring the major or sole purpose of the reservoirs. Besides, the vital water monitoring stations on the Kafue River downstream of the Itezhi-tezhi Reservoir should be wellmaintained in order to provide timely and accurate information about the flow situation. And all possible means of awareness campaigns should be utilised to alert the vulnerable communities or property owners in case of any extreme flow scenarios.

It is important to note that in river basin development and management mankind should ensure to work within the limits of natural processes, the resources could then be utilised to the maximum of their natural limit. However, if man works 'against' nature the results are usually disastrous, and often set up a chain reaction causing a complete breakdown in supply of resources and in society. Development and resource utilisation occur primarily to meet a variety of social needs. River basin development must follow a plan that satisfies social needs without upsetting the physical, ecologic and environmental balance that has previously existed in the basin.

\section{Benefits of the model}

The benefits of using the RAFLS Model will include flood protection, less evaporation from the shallow and wide natural and Kafue Gorge Reservoirs, available grazing grounds for the local communities, reclaimed fertile flood plains for farming by the local people, a favourable flow regime for the ecological requirements, land use and efficient release of water from the reservoirs that would enhance conservation in times of drought.

The model would also make the flow regime of the ITT/ Kafue River system more predictable, resulting in easier watershed planning and management. Hydropower generation planning and operation would also be more efficient by using this model.

\section{Acknowledgements}

The authors wish to thank ZESCO Limited for the provision of the data that were used in the study.

\section{References}

BEVEN JK (2001) Rainfall-Runoff Modelling: The Primer. John Wiley \& Sons Ltd., New York.

CHABWELA HN and ELLENBROEK G A (1990) The impact of hydro-electric developments on the Kafue Lechwe and its feeding grounds at Kafue Flats, Zambia. In: Whigham DF (ed.) Wetland Ecology and Management Case Studies. The Netherlands: Lluwer Academic. 95-105.

CHAPRA SC (1997) Surface Water-Quality Modelling. McGraw-Hill International Editions, Singapore.

COUSENS DWH and BURNEY JR (1976) Small catchment flood modelling Water SA 2 (4) 150. 
DHV CONSULTING ENGINEERS (1980) Kafue Flats Hydrological Studies, Final Report.

FLEMING G (1975) Computer Simulation Techniques in Hydrology. Elsevier Publishing Company, New York.

HANDLOS WL and WILLIAMS GJ (eds.) (1984) Development on the Kafue Flats - The Last Five Years. Kafue Basin Research Committee, University of Zambia, Lusaka.

HARZA ENGINEERING COMPANY INTERNATIONAL LP and RANKIN ENGINEERING CONSULTANTS (1999) Feasibility Study of the Itezhi-tezhi Hydroelectric Project. Vol. 2: Appendices.

REES WA (1978) The ecology of the Kafue Lechwe as affected by the Kafue Gorge Hydro-Electric Scheme. J. Appl. Ecol 15 205-217.

SADC (1993) Itezhi-tezhi / Kafue Gorge Operating Procedure. Final Report, Southern African Development Community, SADC AAA3.4, Hydroelectric Hydrological Assistance Project - Phase 2, Shawinigan Engineering.

SCOTT WILSON PIÉSOLD (2003) Integrated Kafue River Basin Environmental Impact Assessment Study. Scoping Report. Vol. 2: Main Report.
SINYANGWE HM (2004) Flood Prediction Modelling of Kafue River Basin. A research report submitted to the Faculty of Engineering, University of the Witwatersrand in partial fulfilment of the requirements for the degree of Master of Science in Engineering.

STEPHENSON D and RANDELL R (2000) Streamflow Prediction Model for the Orange River Catchment. Resources and Strategy Research Division. Research Report. Company?

STEPHENSON D (2002) RAFLS Rainfall Runoff Event Simulation Model. Water Systems Research Group, University of the Witwatersrand.

WWF (2004) Integrated Water Resources Management Project for the Kafue Flats - Phase 2. Decision Making System for Improved Water Resource Management for the Kafue Flats. Republic of Zambia. Ministry of Energy and Water Development.

ZESCO database: HYDATA Hydrological Database and Analysis System, Version 4.2 (2001) Institute of Hydrology. Centre for Ecology and Hydrology, UK. 
Available on website http://www.wrc.org.za

ISSN 0378-4738 = Water SA Vol. 31 No. 4 October 2005

ISSN 1816-7950 = Water SA (on-line) 